\title{
Social Psychology and the Stimulation of Recycling Behaviors: The Block Leader Approach \\ Shawn M. Burn
}

\begin{abstract}
Recycling has been touted as an important part of the solution to solid waste problems, yet most citizens still do not recycle, even when recycling is made easy by curbside pickups. This field experiment was designed to increase participation in a citysponsored curbside recycling program. Citizens who consistently recycled with the city program were approached and asked to be "recycling block leaders." Those who agreed were instructed to give approximately 10 nonrecycling neighbors a persuasive communication advocating recycling and special recycling bags. A second treatment group (of nonrecycling households) had bags and the communication left at their door. Results indicated that the curbside recycling of the two experimental groups differed significantly from one another (with the block leader group recycling more), and both differed significantly from a control group receiving no treatment. A discussion of past recycling intervention research and its feasibility for community application is included.
\end{abstract}

The recycling of newspapers, cans, and glass was once commonplace in the United States but following World War II, our access to resources seemed unlimited, and many of the systems designed for recycling were dismantled (Schall, 1989). Recycling made a brief comeback during the 1970s following Earth Day but was a only minimal part of waste disposal since resource problems were not yet severe and the cost of landfill disposal was still low, if not free. In addition, recycling at this time was largely the result of concerned environmentalists, not community officials. However, the realities of waste disposal in the eighties have brought about a renewed interest in recycling, this time with the blessing of federal and local officials. For local governments, the incentive to recycle is largely an economic one due to increased landfill disposal costs from expensive environmental safeguards (necessary due to the contamination of water from landfill seepage), new landfill siting problems due to citizen resistance, and high costs due to private ownership of landfills. Today communities commonly pay $\$ 100 /$ ton or more to dispose of trash and solid waste disposal makes up the third largest percentage of a local community's budget (Schall, 1989).

\section{Incentive Approaches to Increase Recycling}

Psychological research on recycling behavior began in the 1970s. Much of the research was conducted by behaviorists who emphasized the use of positive reinforcement strategies. Punishment and negative reinforcement are generally viewed by behaviorists as undesirable ways to create environmentally responsible behaviors since individuals may perceive them as a threat to individual freedom, and this may elicit noncompliance or behavior contrary to that requested (Geller, 1989). Raffle tickets, coupons, and contests have been used as positive reinforcements offered for recycling in college dorms and elementary schools (Couch, Garber, \& Karpus, 1979; Luyben \& Bailey, 1979) and payment for material and eligibility for lottery prizes as positive reinforcers for participation in residential 
recycling programs (Jacobs \& Bailey, 1982-1983).

Unfortunately, once the incentives were taken away, the behavior often underwent extinction (Couch et al., 1979; Luyben \& Bailey, 1979). Pardini and Katzev (1983-1984) explain this with the "over justification effect." Originating with Deci (1975), this name is given to the tendency for external rewards to reduce intrinsic motivation because individuals come to believe that the reason they are performing an activity is for the extrinsic reward. Therefore, when the reward is withdrawn so is the reason for performing the behavior. Interestingly, DeYoung (1985-86) reported that monetary reward was not a dominant motive in a person's decision to recycle, and that intrinsic motivations and satisfactions play an important role in encouraging household recycling. (However, it should be noted that the internal validity of DeYoung's study is suspect due to a $27 \%$ response rate in addition to the selfreport biases common to surveys.)

Incentive approaches to increase recycling have received additional criticisms as well. Not only may they be impractical since they often require continuous monitoring of recycling behavior, but the incentives themselves may be costly and prevent such programs from being cost-effective (Jacobs \& Bailey, 1982-82; Geller, 1989; Stern \& Gardner, 1981). In addition, as Burn and Oskamp (1986) point out, it may be difficult to provide meaningful incentives for every ecologically responsible behavior.

Legislation such as bottle-bills or mandatory recycling programs is also being used to provide incentives for recycling. In the past, passage of legislation has been stymied by concerns about interfering with behavioral freedom, concerns about enforcement, and massive lobbying from industries which may suffer lost revenues as a consequence of such programs. Nine states have passed bottle bills (where people are paid for returning recyclables to collection centers). Although the small amounts offered for returned materials and the inconvenience associated with carting recyclables to collection centers result in many eligible materials going unrecycled, bottle bills are effective in increasing recycling when compared to their absence.

Current legislative efforts have turned to providing funding for curbside recycling programs, some mandatory. While requiring people to recycle may create psychological reactance in some individuals, and the likelihood of punishment for noncompliance is low, recycling is still likely to increase due to the convenience of weekly home pickup and the clear message to citizens that recycling is important and likely to make a difference since so many people are engaging in it. The mandatory recycling program in Woodbury, New Jersey, has been highly successful. There, officials randomly select homes to check for compliance, giving noncompliers first a warning, then refusal to collect their trash for several weeks, then up to a $\$ 300.000$ fine. Woodbury has a participation rate of $98 \%$ and diverts $50 \%$ of its waste stream through recycling (Grogan \& Bell, 1989).

Other cities, such as Claremont, California and San Luis Obispo, California, have been reluctant to require recycling, but encourage it through a weekly curbside collection program where citizens simply separate recyclables and place them at the curb on trash collection day. Unfortunately, participation in these programs is relatively modest, for example, only $29 \%$ of Claremonters participate in that program, therefore research focusing on how to increase participation in them is important. 


\section{Environmental Education and Persuasive Communications}

One of the most common ways to induce ecologically responsible behavior is through the use of educational campaigns. Such campaigns are based on the assumption that humans are rational, and that once supplied with the relevant environmental information, attitudes will change and create behavior changes as well (O'Riordan, 1976). According to O'Riordan and others (Cone \& Hayes, 1980; Heberlein, 1976), these assumptions are faulty and environmental education, even when it changes attitudes, will not necessarily change behavior. Indeed, according to Geller, Winett, and Everett (1982), simple education and advertising procedures have been relatively unsuccessful in encouraging participation in paper recycling programs (Couch et al., 1979; Geller, Chaffee, \& Ingram, 1975a, b; Hamad et al., 1977; Ingram \& Geller, 1975; Witmer \& Geller, 1976).

Social psychologists have outlined a number of reasons why attitudes may not correspond to behavior (Oskamp, 1977; Wicker, 1969). For example, other attitudes may specify competing behaviors (e.g., a pro-convenience attitude might override a prorecycling attitude); the individual may not know how to perform the consistent behavior (e.g., the person with the prorecycling attitude may not know where to take his or her recyclables); and social norms may specify behaviors contrary to a behavior consistent with the individual's attitude.

Although it is true that attitudes and behavior are far from perfectly correlated, having pro-ecology attitudes does increase the likelihood of ecologically responsible behavior. For example, McGuinness, Jones, and Cole (1977) found that level of participation in a recycling program was significantly related to attitudes toward ecology in general, and recycling in particular, and Weigel and Newman (1976) found a general measure of environmental attitudes to predict overall participation in a number of ecology projects. Stern and Oskamp (1987) note that environmental education may work if it is designed to take into account why people engage in environmentally destructive behavior and if it provides counterargumentation.

Education campaigns which also address common reasons for poor attitude-behavior correspondence are likely to be more successful than those that just provide more general information about the seriousness of environmental problems. For example, social psychologists have said that attitudebehavior correspondence is increased when the consistent behavior is easy and less costly to perform (see Oskamp, 1977). Black, Stern, and Elworth (1985) found that attitudes predicted low-cost residential energy improvements but not high-cost ones. While behaviorists avoid reference to attitudes, and perceive them to be relatively superfluous when it comes to behavior change, their research suggests that recycling programs which offer curbside pickup, drop sites in close proximity to residents, and containers which make it easy to separate different kinds of recyclables, should all increase recycling. Reid, Luyben, Rawers, and Bailey (1976) found proximity of containers to increase newspaper recycling in apartment complexes. Humphrey, Bord, Hammond, and Mann (1977) found office worker with wastebaskets divided for recyclables and nonrecyclables recycled more than workers with two separate wastebaskets or those with one wastebasket for recyclables and a centrally located receptacle for other trash. In addition, three studies by Jacobs and Bailey (1979a, 1979b, described in Geller et al., 1982) found recycling to be significantly increased when citizens were supplied with a three-compartment source separation container. 
One of the appeals of environmental education has been that is liked by policymakers and others who are concerned about behavioral freedom and are therefore reluctant to require ecologically responsible behaviors. To these people, the suggestion that persuasive principles be deliberately used in environmental education may be disturbing. However, these principles are in the arsenals of advertising executives and salespeople and as long as the information used is accurate, they should be used by those creating environmental educational campaigns as well. For example, Burn and Oskamp (1986) found a persuasive communication incorporating normative social information (suggested by McGuinness et al., 1977 and Stern \& Kirkpatrick, 1977), accepted beliefs and practices (deemed important by Cook \& Berrenberg, 1981), moderate fear (Rogers, 1975) and specific action suggestions (Leventhal, Singer, \& Jones, 1965) to significantly increase recycling.

\section{Public Commitment Approaches to Increasing Recycling}

In addition to research exploring the effects of incentive approaches on recycling there have been a number of studies examining public commitment techniques. These techniques involve obtaining a verbal or written commitment from the individual to recycle. Commitment techniques are believed to work due to the individual's desire to appear consistent (e.g., it would be inconsistent to say you will do something and then not do it). Supposedly, individuals are motivated to appear consistent since inconsistency is viewed as a socially undesirable trait (Cialdini, 1988).

The "foot-in-the-door" influence technique is one well-documented version of the public commitment technique. The individual is first asked to perform an easy, "low-cost" behavior, and then is later asked to perform larger, related behaviors. Arbuthnot et al., (1977) found that this technique was successful in increasing (self-reported) recycling. Due to the amount of time and difficulty associated with personally approaching numerous individuals multiple times, the technique used by Arbuthnot et al. is impractical for large-scale community use. However, a variation of this technique is used by organizations such as the environmental organization Greenpeace, who mail "surveys" to people known to be sympathetic to their cause, which conclude with a request for a contribution. These campaigns work since agreement with particular survey options function as a small request, and making a contribution is consistent with having responded to the survey in a particular way.

There have been several studies which employed public commitment techniques which do not involve contacting individuals more than once. For instance, Pardini and Katzev (1983-84) significantly increased recycling by having people either verbally agree to recycle newspapers or sign a statement saying they would participate in a newspaper recycling project. The main problem with this technique, however, is that it is probably most effective when the request to commit is made personally, and such personal contacts may be costly if made by paid personnel. Burn and Oskamp (1986) dealt with this problem by having Boy Scouts personally approach citizens and ask them to sign a statement that they would support a community recycling program. They found this technique to significantly increase participation in a curbside recycling program. Geller (1989) presents guidelines for large-scale behavioral interventions and notes that interventions should be delivered through "indigenous personnel" in order to enhance credibility and increase the probability of program maintenance. 


\section{Social Influence Approaches to Increasing Recycling}

Social psychologists have long studied the effects of social norms on behavior. Indeed, one of the first applied social psychological research studies was based on the idea that to produce a lasting change in behavior, it is important to change the social context (Lewin, 1947). In addition, as discussed earlier, attitude-behavior correspondence is increased by attending to the role of social norms in behavior. In regards to recycling, McGuinness, Jones, and Cole (1977), found perceived social support for recycling was related to recycling behavior.

Schwartz (1970) notes that in order for a social norm to predict behavior, the individual must believe that noncompliance will produce negative consequences for others, and in addition must assume personal responsibility for those negative consequences. Weyant (1986) points out that the negative consequences of environmentally destructive behaviors are not usually apparent. For example, most residents do not live by the landfill which ultimately houses their solid waste. Furthermore, personal responsibility is reduced because individuals feel that "nobody else is performing the behavior either" and that they have no choice but to perform the environmentally irresponsible act.

The field experiment discussed below used what may be called the "block leader" approach to increase recycling. Individuals who already participated in a city's curbside recycling program were asked to deliver persuasive communications and recycling bags to their nonrecycling neighbors to engender a neighborhood recycling norm. Note that the use of block leaders communicates that "other people are doing it" and reminds individuals that they do have some choice regarding their waste disposal.

Awareness that neighbors are recycling may not only suggest that an action is more likely to make a difference (since others are presumably performing it also), but may lead to performance due to a desire for social approval. Cook and Berrenberg (1981) discuss the role of "social incentives" in encouraging resource conservation behaviors, noting that behavior is motivated and reinforced by social as well as material incentives. They write about the role of social recognition and approval as motivators and how contact with others may be instrumental in gaining a commitment to perform a behavior.

In addition, recycling neighbors may serve as models. To borrow from Krebs (1970), models (in this case, recycling block leaders) may make behavioral alternatives salient and highlight social norms and provide information about the consequences of a behavior. Personal contact with block leaders is also likely to result in a verbal public commitment to participate in a city recycling program and, as discussed above, commitment techniques have been demonstrated to be effective in eliciting ecologically responsible behaviors.

According to Rogers (1983), at the heart of the process of diffusion of an innovation is the modeling and imitation by potential adopters of their near-peers who have adopted an idea. Similarly, Darley and Beniger (1981) claim that "the decision to adopt or reject any particular innovation is determined to a large extent by the interpersonal networks surrounding the potential adopter" (p. 152). Darley (1978) provides some evidence that the spread of energy-conservation innovations proceeded by the structure of social networks (e.g., people at work) rather than spatial ones (these days, neighbors are not necessarily friends or even acquaintances). The block leader approach is one way to facilitate diffusion of household information in neighborhoods without good social networks. 
Nielson and Ellington (1983) report on a version of the block leader approach where individuals promoted recycling in their own neighborhoods by encouraging new households to recycle and reminding neighbors of upcoming pickup dates. They found that participation rates were significantly higher in blocks with leaders than without. Unfortunately, the study description suggests that blocks were not randomly assigned to the treatment and control groups and that block leaders were an unusual group of individuals who originally formed to save a city recycling program from demise.

The present research study attempts to remedy the shortcomings of the Nielson and Ellington study through the use of random assignment of homes to receive a block leader treatment or simple exposure to a persuasive communication advocating participation in a city's curbside recycling program. Furthermore, as advocated by Geller (1989), the study used "indigenous personnel." The study is an example of applied social psychology as described by Weyant (1986). It is not designed to test theory but rather to test an intervention whose design was influenced by a number of different theories.

\section{Method}

Summary of Design

This randomized field experiment had two treatment conditions and a control group receiving no treatment. One treatment group consisted of neighborhood block leaders who delivered persuasive communications and recycling bags to nonrecycling neighbors to increase participation in a citywide, curbside recycling program. The other treatment group consisted of nonrecycling households who had persuasive communications and recycling bags left at their doors.

\section{Sample}

A sample of households from Claremont, California (located in Southern California) was studied. The importance of a representative sample to external validity was explained to city officials. These officials then provided the researcher with a sample of city neighborhoods (complete with a list of addresses) which they felt adequately represented the city demographically. The officials also agreed to provide the personnel to record curbside recycling, providing it took an hour or less each day. Consequently, sample size was restricted to approximately 200 homes.

\section{Materials}

Persuasive communication. A modified version of the persuasive communication found by Burn and Oskamp (1986) to increase recycling was used in the two treatment conditions. This persuasive communication combined those factors found by laboratory experimenters to increase persuasion and was not intended to test a single persuasive factor. For example, moderate fear (Hass, Bagley, \& Rogers, 1975; Leventhal, 1970) was operationalized by describing how much trash the average household produces and how the local landfill is scheduled to close in just a few years. The specific actions desired (Leventhal, Singer, \& Jones, 1965) were emphasized by a complete description of how to participate in the city's recycling program and, the efficacy of the action (recycling) in reducing the fear (Rogers, 1975) was emphasized. A normative social information component was supplied by emphasizing 
community support for the recycling program, identifying the adverse social consequences of current waste disposal behaviors, and stating the individual's contribution to the solid waste problem (factors suggested by Schwartz, 1970). The text of the communication was as follows:

\section{CLAREMONT IS RECYCLING}

As a U.S. citizen you probably show your support for our country by voting and paying taxes. Beyond this you may feel there is nothing more you can do. However, there are things you can do. One of these is participation in Claremont's recycling program.

Californians alone produce some 40 million tons of refuse a yearenough to fill a two-lane highway, ten feet deep from Oregon to the Mexican border. Currently, the average person in the U.S. produces about 1,300 lbs. of solid municipal waste a year. Most of this trash goes into landfills, and it is estimated that if present trends continue, nearly all of L.A. County will be without refuse disposal capacity by 1991 .

RECYCLING uses wastes instead of filling up landfills.

RECYCLING extends resource supplies.

RECYCLING IS EASY ... SIMPLY PUT NEWSPAPERS, ALUMINUM, AND GLASS INTO SEPARATE BAGS AND PLACE AT THE CURB ON YOUR REGULAR TRASH COLLECTION DAY.

Recycling makes a difference and recycling is happening. Over $80 \%$ of Claremonters favor the City's recycling program and other cities are calling to ask how Claremont does it. Help us do it, please recycle.

Recycling bags. Subjects in the experimental groups received three orange net recycling bags with the city logo in which to place each type of recyclable. Once a week, on trash collection day, recycling collectors empty the bags into a specially designed truck and leave the emptied bags at the householder's curb.

Block leader packet. Block leaders received a large envelope containing the following:

1. A block leader checklist-a list of the addresses of nonrecycling neighbors, with spaces to record the date and time of contact, and whether the contact was made in person, by phone, or by leaving the intervention materials at the door with a personal note.

2. An instruction sheet-instructed the block leader to give each household contacted a recycling information sheet, three recycling bags, and a personal note if no one was at home after several tries. This sheet also instructed blockleaders to introduce themselves as a neighbor and explain their appointment by a city committee as "recycling block leader," and then to verbally explain how important 
recycling is, how easy it is to recycle with the city program, and to point out the list on the back of the communication specifying the materials recycled by the city. This "speech" was to end with "I hope to see your bags out at the curb in a few weeks."

3. Enough persuasive communications for each address on the list.

4. A self-addressed stamped envelope so that the completed checklist could be mailed back to the researcher.

Baseline data. In order to determine which households were recycling with the city program and which were not, the curbside recycling of each household in the sample was observed on the weekly trash collection day for the first four weeks of March, 1989. Baseline observations were made by a college senior doing an internship with the city. The researcher travelled the entire route with the data collector prior to the data collection period, helping her to identify recyclables and explaining the importance of accuracy.

Manipulation of the independent variable. Households were grouped by blocks of approximately 10 homes each and blocks were randomly assigned to one of three groups: a group to be contacted by a recycling neighbor with persuasive communications and bags (Block Leader Group); a group to receive communications and bags at the door (Door Only Group); or a control group receiving no treatment.

Households which had recycled at least once during the baseline period from blocks assigned to the "Block Leader" condition, were contacted on Friday, March 31, and Saturday, April 1 between 3:00 and 5:00 p.m. The researcher would knock on the door, introduce herself as working on a project to increase recycling for the City, and said something like this: "We've noticed your recyclables at the curb on trash day and we wish that there were more people like you. Out latest strategy to increase recycling is to have people who are already recycling explain to their neighbors how easy and important it is. I've got a list right here of ten of your nonrecycling neighbors, would you be willing to be a recycling block leader?" This verbal request used consistency principles by implying that being a block leader would be consistent with past recycling behavior (see Cialdini, (1988) for an entertaining discussion of the role of consistency in influence tactics).

Seven individuals (four females, three males), and one married couple readily agreed to be block leaders. Immediately upon agreement, the block leader packet was explained. Block leaders were asked to try and approach their neighbors within 2 weeks. If, after 3 weeks, the completed checklist had not been received by the researcher, a brief written query was sent. This resulted in the return of all checklists.

Of these approached and asked to be block leaders, six declined. Reasons for refusal were varied and included: "I'll be out of town in the next 2 weeks"; "We don't do that sort of thing"; "My health will not permit it"; "I've been having problems getting the city to pick up my recyclables"; and one unexplained refusal from a recent immigrant to this country. All refusals were from males with the exception of two. In the case of refusal, another recycling household on the same block was approached. This approach worked well with the exception of two neighboring blocks for which all eligible households declined participation. Unfortunately, these refusals reduced the size of this treatment group by approximately 20 
households. The block leader group was further reduced by a potential block leader who could not be contacted after two visits and nine households which were unable to be contacted by block leaders. As a result, only 41 homes received the block leader treatment.

Recycling bags and persuasive communications were delivered to 68 homes in the "Door Only Group" on Monday, April 3, 1989. The control group consisted of 104 homes.

Posttreatment data collection. The curbside recycling of the two experimental groups and one control group was observed for a total of 12 weeks following intervention. However, a household's recycling behavior was not used to ascertain the effectiveness of treatment until one week following the date given by the block leader as the date of contact, or in the case of the "Door Only Group," one week following delivery of bags and communications. This was done so that households would have time to accumulate some recyclables. This meant that most households were observed a total of 11 weeks following treatment. It should be noted that each observation was bivariate (recyclables at the curb or not) since resources were insufficient to record types and amounts of recyclables present.

Posttreatment data were collected by a policy analyst from the city's community service department, trained by the researcher using the same method used to train the baseline data collector. Experimenter bias was reduced since the researcher did not collect the data, households were not identified by treatment group on the data collection sheets, and the presence of recyclables at the curb was easily discernable due to the orange recycling bags used.

\section{Results}

Table 1 reports the percentage of each group recycling over a 10-week posttreatment period. The weekly means of the three groups strongly support that the block leader treatment was most effectivean average of $28 \%$ of these homes recycled weekly in comparison to almost $12 \%$ of the "Door Only" group and $3 \%$ of the control group. The figures in Table 1 also indicate persistent treatment effects since rates of recycling did not show significant erosion as the posttreatment period progressed. Slightly over $58 \%$ of those receiving the block leader treatment recycled at least once during the posttreatment period, $38 \%$ of the "Door Only" group, and $19.6 \%$ of the control group.

An analysis of variance procedure with a priori contrasts was used to compare the recycling of the three groups and found them to differ significantly $(F=21.12$, d.f. $=2,208, \mathrm{p}<.001)$. The mean number of times each of the three groups recycled was: Block Leader, 2.73, $n=41$ (95\% C.I. for mean, 1.77 to 3.68); Door Only, 1.32, $\mathrm{n}=68$, (95\% C.I. .79 to 1.84); and Control, .362, $\mathrm{n}=102$ (95\% C.I. .16 to .56). The Block Leader group recycled significantly more than the Door Only group $(t=4.00, \mathrm{p}<.001)$ and the control group $(\mathrm{t}=6.91, \mathrm{p}<.0001)$, while the Door Only group recycled significantly more than the control group $(t=3.10, \mathrm{p}<.01)$ :

There were also nine households which could not be personally contacted by block leaders. Block leaders then left the bags and information sheet, along with a personal note, at the door. Six of the nine households contacted in this way began recycling (66\%). However, the size of this group was too small to permit any definitive conclusions about the effectiveness of this particular treatment. 


\section{Discussion}

The data indicated that both the block leader approach and simply leaving a persuasive communication and recycling bags at the door of nonrecycling households were successful in increasing recycling. Both of these interventions are relatively inexpensive yet if implemented would result in great savings to the city. The city official in charge of calculating waste disposal costs estimated that if $50 \%$ of Claremont's citizens recycle, it would result in additional monthly revenues of $\$ 9200.00$ and an additional $\$ 2400.00$ a month in avoided landfill costs (58\% of those receiving the block leader treatment recycled and $38 \%$ of those who had the communication left at their door recycled). Implementing the interventions would require only a small fraction of this amount. Both programs would initially require some staff or volunteer time to monitor curbside recycling in order to identify nonrecyclers and in the case of the block leader approach, potential block leaders (data may be collected on several hundred homes in an hour's time and a high-level staff person is not needed). The block leader approach is more expensive due to the contacting of the block leaders (it took approximately three to four hours to obtain the eight leaders for this study). However, members of local environmental citizen groups or interns from local colleges could be used for this task. The duplication of block leader lists is an additional but relatively low cost as well. In spite of these costs, the greater effectiveness of the block leader approach may outweigh the additional expenses.

Either approach could be gradually implemented until all community areas had been reached. This way, the intervention would require a minimal amount of staff time and organizational change, and the increase in overall recycling would be gradual enough so that the increased volume would not put a strain on existing personnel or resources.

The effectiveness of the treatments may have been enhanced by the increased media attention to the waste disposal problem that coincided with the study period. This could have caused individuals to be sensitive to the need for recycling and capitalized on their intentions to do so. This possibility is suggested by the rather large percentage of the untreated control group that began recycling (19\%). While it is conceivable that there was some diffusion of treatment if block leaders or those contacted by block leaders spoke to additional neighbors about the city program, this possibility was lessened due to the fact that blocks, rather than individual homes, were randomly assigned to treatment conditions.

Due to the use of random assignment and a control group, we can feel confident about the internal validity of the study. However, it should be noted that the external validity of the study is affected by the relative affluence and racial and educational homogeneity of the community studied (a largely white, college educated population with a median income of approximately \$28,000). It is not known whether the techniques discussed here would work equally well in a more diverse, metropolitan area and this is an important area for study. Future researchers/interveners may also consider having the block leader have nonrecycling neighbors sign a statement supportive of recycling to further enhance commitment.

While the results clearly demonstrate the effectiveness of the block leader treatment, it remains unclear exactly which social psychological principle is responsible for its success. As discussed in the introduction, the block leader approach may work due to the influence of modeling or the suggestion that one's action is more likely to make a difference since others are doing it; it may operate as a social incentive by providing social recognition for the behavior; or it may work because the block leader is 
likely to get a verbal commitment from his or her neighbors. It is also possible that in some cases it works for one of these reasons, while in other cases it works due to another. Admittedly, this makes the treatment a sort of "black box." This is not uncommon in applied research as noted by Weyant (1986), who stated that the independent variable in applied research is often quite complex and leaves ambiguity about which part, or parts, of it produced the effect. In comparison to traditional social psychology, applied social psychology is not so much about the testing of theories and concepts as it is about testing interventions. The design and testing of practical interventions inspired by social psychological principles is a logical extension of a discipline which concerns itself with socially relevant concepts.

\section{Directions for Future Research}

In the future social psychologists may need to take more of a systems perspective where we examine the various interrelated social systems which would be necessary for the large-scale adoption of fieldtested interventions. For instance, past research suggests that commitment techniques, persuasive communications, and normative appeals have the potential to significantly change behavior if applied on a large scale. Such applications may require a better understanding of how to organize citizens to deliver interventions and persuade policymakers to provide funding, an area which has received little attention from social psychologists. Similarly, relatively simple interventions that make recycling easier (e.g., special containers) and more convenient (proximity of drop sites, or curbside pickup) seem to significantly affect recycling behavior but need government funding and support.

As society's experts on changing maladaptive behavior, psychologists have a heightened responsibility to share what they know in order to reduce the severity of serious social and environmental problems. This is certainly not a simple matter. Those considering such interventions should be aware of several things. First, community officials often know little about behavior and may resist our recommendations. Second, they often know little about research and won't understand the importance of representative sampling and long-term monitoring of behavior. Third, since there are usually no extra organizational resources to devote to the extension of demonstration projects to the larger community, our findings may go unused. While these three things are indeed obstacles, they are by no means insurmountable. For example, if psychologists offer to conduct research at little or not cost to cities, officials tend to be more compliant. And, if we offer to oversee the large-scale application of our recommendations or provide officials with the step-by-step instructions necessary to do so themselves, our findings are more likely to be used.

In conclusion, to paraphrase Stern and Oskamp (1987), we should design our research on ecologically responsible behaviors so that it will provide a helpful empirical basis for policy. Our interventions should be inexpensive, and easy enough for communities and governments to apply at a large scale. Furthermore, we should assist in the application of psychological principles past the demonstration level. 


\section{References}

Arbuthnot, J., Tedeschi, R., Wayner, M., Turner, J., Kressel, S., \& Rush, R. (1977). The induction of sustained recycling behavior through the foot-in-the-door technique. Journal of Environmental Systems, 6, 353-366.

Black, J.S., Stern, P.C., \& Elworth, J.T. (1985). Personal and contextual influences on household energy adaptations. Journal of Applied Psychology, 70, 3-21.

Burn, S.M. \& Oskamp, S. (1986). Increasing community recycling with persuasive communication and public commitment. Journal of Applied Social Psychology, 16, 29-41.

Cialdini, R. (1988). Influence: Science and practice, (2nd Ed.). Boston: Scott-Foresman.

Cone, J.D. \& Hayes, S.C. (1980). Environmental problems/Behavioral solutions. Monterey, CA: Brooks-Cole.

Cook, S.W. \& Berrenberg, j.L. (1981). Approaches to encouraging conservation behavior: A review and conceptual framework. Journal of Social Issues, 37, 73-107.

Couch, J.V., Garber, T., \& Karpus, L. (1979). Response maintenance and paper recycling. Journal of Environmental Systems, 8, 127-137.

Darley, J.M. (1978). Energy conservation techniques as innovations and their diffusion. Energy and Buildings, 1, 339-343.

Darley, J.M. \& Beniger, J.R. (1981). Diffusion of energy-conserving innovations. Journal of Social Issues, 37, 150-171.

Deci, E.L. (1975). Intrinsic motivation. New York: Plenum.

DeYoung, R. (1985-86). Encouraging environmentally appropriate behavior: The role of intrinsic motivation. Journal of Environmental Systems, 15, 281-291.

Geller, E.S. (1989). Applied behavior analysis and social marketing: An integration for environmental preservation. Journal of Social Issues, 45, 17-36.

Geller, E.S., Chaffee, J.L., \& Ingram, R.E. (1975a). Promoting paper recycling on a university campus. Journal of Environmental Systems, 5, 39-57.

Geller, E.S., Chaffee, J.L., \& Ingram, R.E. (1975b). Promoting paper recycling on a college campus. Journal of Environmental Systems, 8, 127-137.

Geller, E.S., Winett, R.A., \& Everett, P.B. (1982). Saving the environment. New York: Pergamon.

Grogan, P., \& Bell, R. (1989). Local impact of state recycling laws. Bio Cycle, 30, 50-55.

Hass, J.W., Bagley, G.S., \& Rogers, R.W. (1975). Coping with the energy crisis: Effects of fear appeals upon attitude toward energy consumption. Journal of Applied Psychology, 60, 754-756.

Heberlein, T.A.S. (1976). Some observations on alternative mechanisms for public involvement. The hearing, the public opinion poll, and the quasi-experiment. Natural Resources Journal, 16, 197212.

Humphrey, C.R., Bord, R.J., Hammond, M.M., \& Mann, S. (1977). Attitudes and conditions for cooperation in a paper recycling program. Environment and Behavior, 9, 107-124.

Ingram, R.E. \& Geller, E.S. (1975). A community integrated, behavior modification approach to facilitating paper recycling. JSAS Catalog of Selected Documents in Psychology, 5, 327 (ms. No. 1097). 
Jacobs, H.E. \& Bailey, J.S. (1979a). A preliminary analysis of motivational factors in a residential recycling program. Symposium conducted at the Southeastern Psychological Association meeting, New Orleans, Louisiana.

Jacobs, H.E.\& Bailey, J.S. (1979b). The Leon County recycling program. Symposium conducted at the Southeastern Psychological Association meeting. New Orleans, Louisiana.

Jacobs, H.E. \& Bailey, J.S. (1982-83). Evaluating participation in a residential recycling program. Journal of Environmental Systems, 12, 141-152.

Krebs, D.L. (1970). Altruism - an examination of the concept and a review of the literature. Psychological Bulletin, 73, 258-302.

Leventhal, H. (1970). Findings and theory in the study of fear communications. In L. Berkowitz (Ed.), Advances in experimental social psychology (Vol. 5). New York: Academic Press.

Leventhal, H., Singer, R., \& Jones, S. (1965). Effects of fear and specificity of recommendation upon attitudes and behavior. Journal of Personality and Social Psychology, 2, 20-29.

Lewin, K. (1947). Group decisions and social change. In T. Newcomb \& E. Hartley (Eds.), Readings in social psychology. New York: Holt, Rinehart and Winston.

Luyben, P.D. \& Bailey, J.S. (1979). Newspaper recycling: The effects of rewards and proximity of containers. Environment and Behavior, 11, 539-557.

McGuiness, J., Jones, A.P., \& Cole, S.G. (1977). Attitudinal correlates of recycling behavior. Journal of Applied Psychology, 62, 376-384.

O'Riordon, T. (1976). Attitudes, behavior, and environmental policy issues. In I. Altman \& J.F. Wohlwill (Eds)., Human behavior and environment: Advances in theory and research (Vol. 1). New York: Plenum.

Oskamp, S. (1977). Attitudes and opinions. Englewood Cliffs, NJ: Prentice-Hall.

Pardini, A.U. \& Katzev, R.D. (1983-84). The effect of strength of commitment on newspaper recycling. Journal of Environmental Systems, 13, 245-254.

Reid, D.H., Luyben, P.D., Rawers, R.J., \& Bailey, J.S. (1976). Newspaper recycling behavior: The effects of prompting and proximity of containers. Environment and Behavior, 8, 471-482.

Rogers, E.M. (1983). Diffusion of innovations (3rd ed.). New York: Free Press.

Rogers, R.W. (1975). A protection motivation theory of fear appeals and attitude change. Journal of Psychology, 91, 93-114.

Schall, J. (1989, June). Socialist ecology—capitalist garbage. Zeta, pp. 69-72.

Schwartz, S.H. (1970). Moral decision-making and behavior. In J. Macaulay \& L. Berkowitz (Eds.), Altruism and helping behavior. New York: Academic Press.

Stern, P.C. \& Gardner, G. T. (1981). Psychological research and energy policy. American Psychologist, 36, 329-342.

Stern, P.C. \& Kirkpatrick, E.M. (1977). Energy behavior: Conservation without coercion. Environment, 10, 10-15.

Stern, P.C. \& Oskamp, S. (1987). Managing scarce environmental resources. In I. Altman and D. Sotkols (Eds.), Handbook of environmental psychology, pp. 1044-1088.

Weigel, R.H. \& Newman, L.S. (1976). Increasing attitude-behavior correspondence by broadening the 
scope of the behavioral measure. Journal of Personality and Social Psychology, .33, 793-802.

Weyant, J.M. (1986). Applied social psychology. New York: Oxford. Witmer, J.F. \& Geller, E.S.

(1976). Facilitating paper recycling: Effects of prompts, raffles, and contests. Journal of Applied Behavior Analysis, 9, 315-322.

Table 1

Percentage of Homes Recycling After Treatment

\begin{tabular}{cccc}
\hline & $\begin{array}{c}\text { Condition } \\
\text { Block leader } \\
(n=41)\end{array}$ & $\begin{array}{c}\text { Door only } \\
(n=68)\end{array}$ & $\begin{array}{c}\text { Control } \\
(n=102)\end{array}$ \\
\hline Overall & 58 & 38 & 20 \\
WEEK & & & \\
1 & 23 & 3 & 4 \\
2 & 32 & 10 & 2 \\
3 & 25 & 13 & 6 \\
4 & 25 & 18 & 0 \\
5 & 23 & 12 & 6 \\
6 & 29 & 7 & 0 \\
7 & 28 & 13 & 2 \\
8 & 42 & 15 & 6 \\
9 & 34 & 13 & 2 \\
10 & 23 & 13 & 3 \\
Weekly mean & 28 & 12 & 2 \\
\hline
\end{tabular}

Note. "Overall" category refers to percentage of homes that recycled one or more times. 